\title{
Computational Fluid Dynamics Simulation Study of a Novel Membrane Contactor for Simultaneous Carbon Dioxide Absorption and Stripping
}

\author{
Hsuan Chang *, Hau-Yu Gan, Yih-Hang Chen and Chii-Dong Ho \\ Energy and Opto-Electronic Materials Research Center, Department of Chemical and Materials Engineering, \\ Tamkang University, Tamsui, New Taipei 251, Taiwan; larry12900081@yahoo.com.tw (H.-Y.G.); \\ yihhang@mail.tku.edu.tw (Y.-H.C.); cdho@mail.tku.edu.tw (C.-D.H.) \\ * Correspondence: nhchang@mail.tku.edu.tw; Tel.: +886-2-2621-5656 (ext. 3282); Fax: +886-2-2620-9887 \\ Academic Editor: Gustavo Fimbres Weihs \\ Received: 4 July 2017; Accepted: 31 July 2017; Published: 2 August 2017
}

\begin{abstract}
Physical absorption is a potential technology for economic carbon capture due to its low energy consumption, however, the absorption efficiency of current systems must be improved. In this study, novel hybrid absorption/stripping membrane contactors (HASMCs) for physical solvent carbon capture are proposed. The simultaneous absorption and stripping within one module provides instant regeneration of the solvent and results in the enhancement of absorption. HASMCs with parallel-flow and cross-flow configurations and using empty or spacer-filled channels are investigated by rigorous computational fluid dynamics simulation. The internal profiles of transmembrane mass fluxes reveal that cross-flow HASMCs are much more effective than the parallel-flow ones and the modules using spacer-filled channels give better performance than the ones using empty channels. The mass transfer coefficients of HASMCs are much higher than predicted by correlations in the literature.
\end{abstract}

Keywords: carbon capture; membrane contactor; absorption; stripping; computational fluid dynamics

\section{Introduction}

Carbon capture and storage (CCS) has been identified as an essential technology to meet the internationally agreed goal of limiting the temperature increase to $2{ }^{\circ} \mathrm{C}$ [1]. Fossil fuel power plants will remain a major contributor to carbon dioxide emissions. The state-of-the-art technology for post-combustion $\mathrm{CO}_{2}$ capture (CC) is chemical absorption using amine solvents. However, because the chemical solvents must be thermally regenerated with consumption of a significant amount of energy, employing chemical absorption technology in power plants can cause the cost of electricity (COE) to increase by up to 75\% [2]. Contrary to chemical absorption, physical absorption solvents are generated by reducing operation pressure and does not suffer for high energy consumption [3]. Nevertheless, because of the low partial pressure of carbon dioxide in the flue gas, physical absorption technology is not an economical technology for post-combustion carbon capture. The enhancement of physical absorption efficiency for post-combustion flue gas can possibly facilitate the realization of the R\&D goal of carbon capture technology, i.e., the increase of COE to be less than 35\% [2].

Membrane contactors, employing non-selective membranes between fluid phases, can serve as strippers, absorbers, extractors and distillation devices [4]. Compared to conventional gas-liquid equipment, such as tray or packed towers, the advantages of membrane contactors are: (1) high specific area/reduced size of equipment, (2) no hydraulic problems, such as flooding, channeling or weeping, and (3) complete loading/fully utilization of interface area [5]. The major potential disadvantage of membrane contactors is their slower mass-transfer due to membrane resistance [5]. 
Numerous experimental [6-9] and modeling [10-13] studies of membrane contactors for carbon dioxide absorption and stripping using various physical and chemical solvents have proven the feasibility of the application and the capability of analyzing the performance using mathematical models developed from first principles.

Various methods have been proposed for enhancing the performance of membrane modules. Yang et al. [14] developed modified hollow fiber modules employing baffles in the shell side, wavy shape fiber or fiber with gear-shaped cross section. Ho et al. studied membrane modules with rough-surface channels [15]. Hoff and Svendsen [12] pointed out that the simplest way of enhancing liquid mixing is to pass the liquid on the shell side, across the fiber bundle, and the gas flow on the tube side. Spacers are commonly used as turbulence promoters in membrane distillation modules $[16,17]$.

The advances in scientific computing and commercial computational fluid dynamics (CFD) packages have resulted in rapid progress in the applications of CFD in performance analysis, design and optimization of various equipment and systems. For membrane distillation using spacer-filled channels, Shakaib et al. [18] conducted CFD simulations to study the effects of spacer orientation and filament spacing on shear stress and temperature polarization. Yang et al. [14] reported CFD simulations of hydrodynamics and temperature polarization of special designed hollow fibers in membrane distillation modules. For membrane distillation modules employing roughened surface channels and spacer-filled channels, local heat transfer coefficients were obtained via CFD simulation $[19,20]$. For absorption of carbon dioxide using membrane modules with net spacers, Lou et al. [21] used CFD simulation to investigate the effects of spacer geometric parameters on velocity field and pressure drop.

This paper presents a novel membrane module design concept, called the hybrid absorption/stripping membrane contactor (HASMC), to enhance the performance of carbon capture using physical solvents. The simultaneous absorption and stripping can enhance the effectiveness of carbon capture. In this study, CFD simulation was employed to investigate the mass transfer characteristics inside the HASMCs, including the concentration boundary layers and the transmembrane mass fluxes. Four types of HASMCs were studied, including the parallel-flow and cross-flow configurations using either empty channels or spacer-filled channels. The physical absorbent chosen for this study is propylene carbonate, which is the solvent employed in the commercial Fluor carbon capture process [3].

\section{Hybrid Absorption/Stripping Membrane Contactor (HASMC)}

For simultaneous absorption and stripping, parallel-flow and cross-flow HASMCs were proposed and analyzed in this study. In the parallel-flow module, both flue gas/absorbent liquid and absorbent liquid/stripping gas employ a countercurrent-flow arrangement, as depicted in Figure 1. In the cross-flow module, both flue gas/absorbent liquid and absorbent liquid/stripping gas employ a cross-flow arrangement and the flue gas and stripping gas channels are adjacent to each other and the flow directions are countercurrent, as illustrated in Figure 2. The simulated cross-flow module, as shown in Figure 2, includes two sets of flue gas and stripping gas channels and a single absorbent liquid channel.

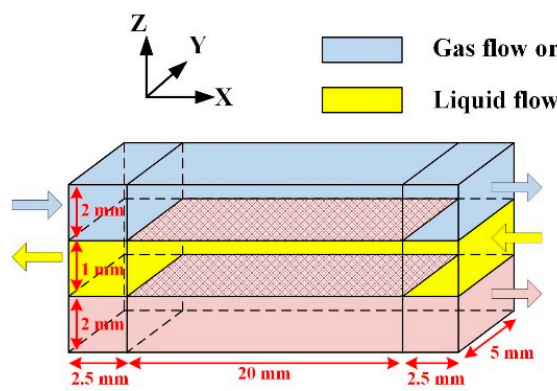

(a) PE-HASMC

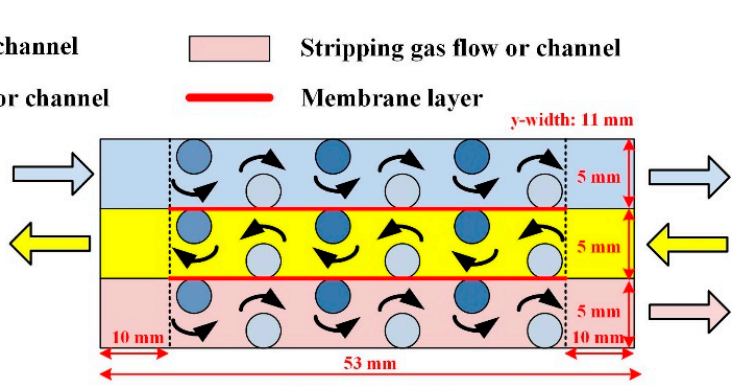

(b) PS-HASMC

Figure 1. Parallel-flow hybrid absorption/stripping membrane contactors (HASMCs) with (a) empty channels or (b) spacer-filled channels. 


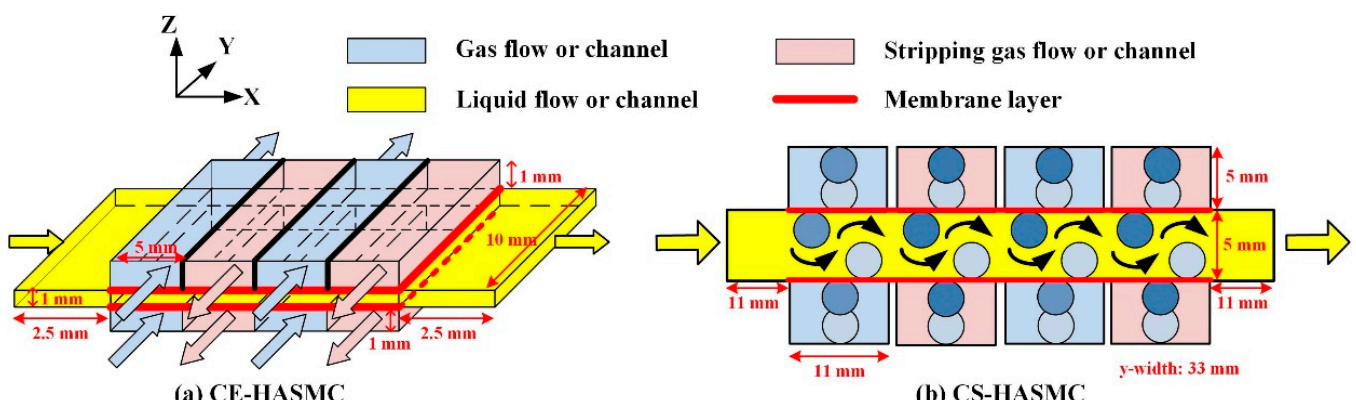

Figure 2. Cross-flow HASMCs with (a) empty channels or (b) spacer-filled channels.

In both Figures 1 and 2, two schematic plots are presented to show the modules use either empty channels or spacer-filled channels. The net-type spacer used is shown in Figure 3. Hereafter, the four types of HASMC are referred as PE-HASMC (parallel-flow with empty channels), PS-HASMC (parallel-flow with spacer-filled channels), CE-HASMC (cross-flow with empty channels) and CS-HASMC (cross-flow with spacer-filled channels).

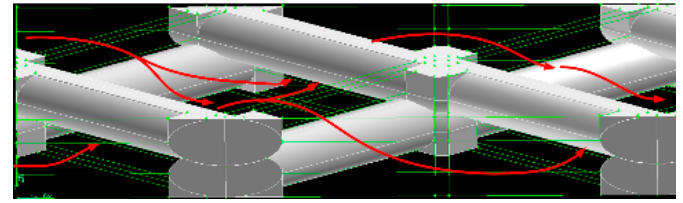

(a)

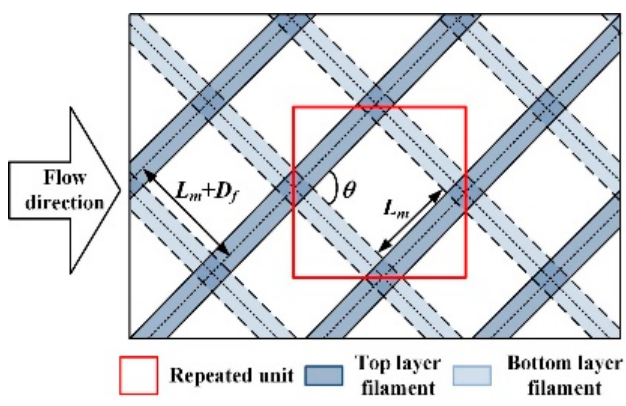

(b)

Figure 3. The flow paths (a) and geometric characteristics (b) of the net-type spacers.

The mass transfers inside parallel-flow and cross-flow HASMCs are illustrated in Figure 4. In the parallel-flow configuration, as shown in Figure $4 \mathrm{a}$, the absorption membrane and the stripping membrane are located on opposite sides of the absorbent liquid. In the cross-flow configuration, as shown in Figure $4 \mathrm{~b}$, the absorption membrane and the stripping membrane are adjacent to each other and allocated on the same side of the absorbent liquid. In the parallel-flow configuration, the concentration boundary layers at the absorption and stripping membrane boundaries are separated by the bulk liquid. Differently, in the cross-flow configuration, the concentration boundary layer of the absorption section is followed by that of the neighboring stripping section.

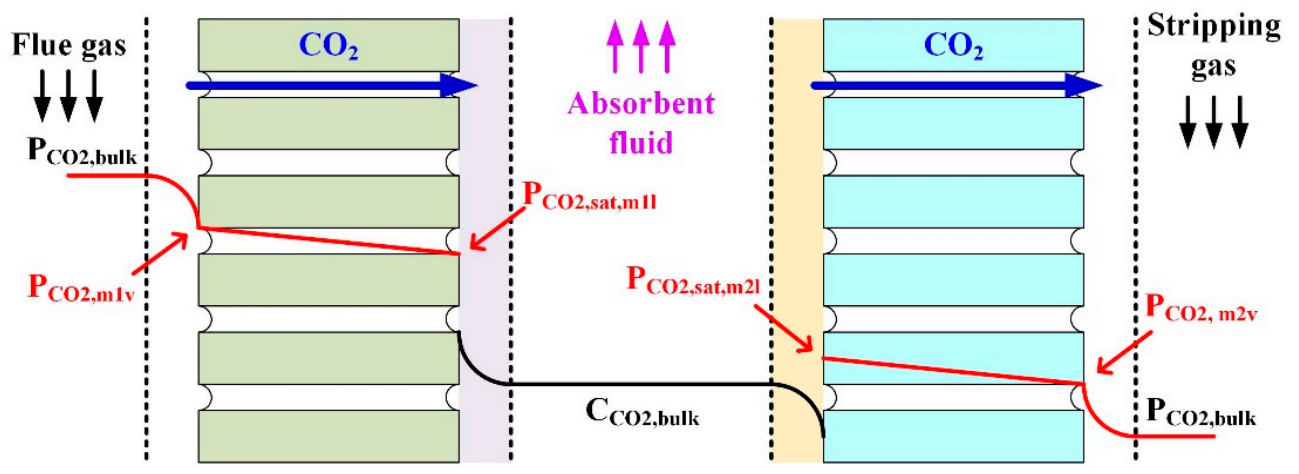

(a)

Figure 4. Cont. 


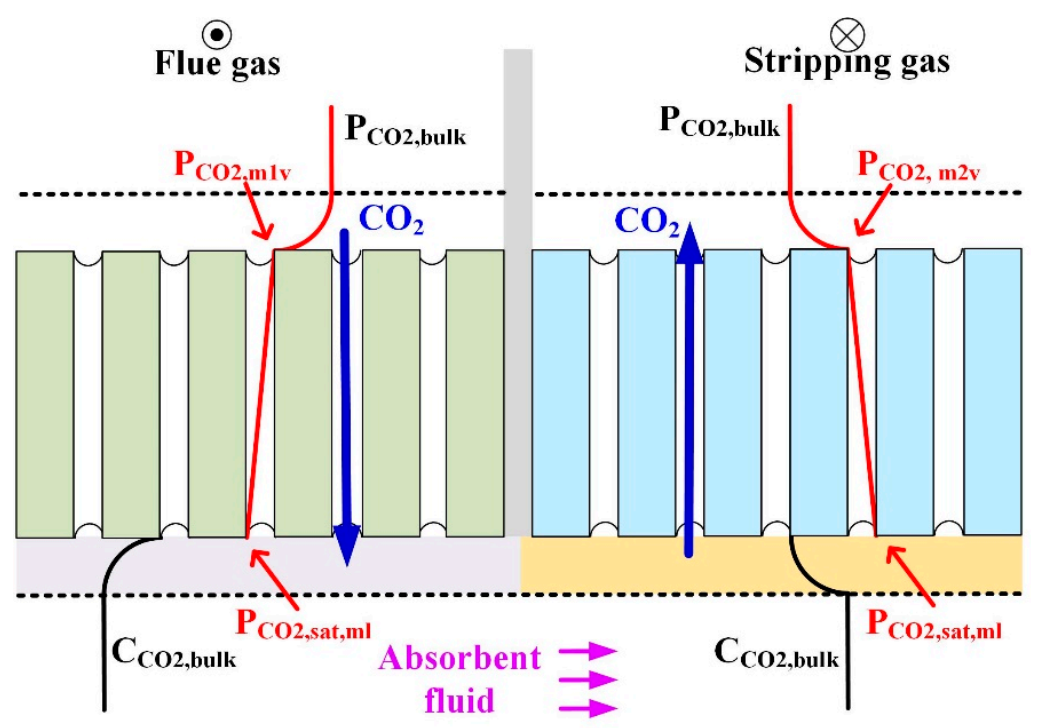

Flow out of the plane of the paper

$\otimes$ Flow into the plane of the paper

(b)

Figure 4. Mass transfers in (a) parallel-flow and (b) cross-flow HASMCs.

\section{Modeling}

The CFD simulation takes into account the transmembrane mass transfer of carbon dioxide and the thermodynamics of carbon dioxide/propylene carbonate system. For the flow in empty channels, the operation conditions fall within the laminar flow regime. For flow and mass transfer in narrow spacer-filled channels, Fimbres-Weihs and Wiley [22] pointed out that the flow conditions are laminar in nature and can be simulated without the need to employ turbulent models. The laminar flow model of FLUENT 6.3 and the grid generation preprocessor GAMBIT were used for the 3D CFD simulation of this study.

\subsection{Computational Domain and Grids}

The dimensions of the simulated HASMC modules are shown in Figures 1 and 2. At the entrance and exit of each module, a small extra length was added to simulate the actual module in order to avoid convergence difficulty. In these extra zones, the interface between the top and bottom channels is a non-permeable solid wall instead of a porous membrane. The hydrodynamic angles $(\theta)$, mesh size $\left(l_{m}\right)$ and filament diameter $\left(D_{f}\right)$, as defined in Figure 3, of the spacers used are $90^{\circ}, 8 \mathrm{~mm}$ and $3 \mathrm{~mm}$. The membrane used for this study is a polyether ether ketone (PEEK) membrane with a permeation coefficient of $1000 \mathrm{GPU}\left(1 \mathrm{GPU}=1 \times 10^{6} \mathrm{~cm}^{3}(\mathrm{STP}) / \mathrm{cm}^{2} / \mathrm{s} / \mathrm{cm} \mathrm{Hg}\right)$ [23].

Structured hexahedral grids were used in the empty channel as well as the outer parts of the entrance and exit sections of all modules. Unstructured tetrahedral cells were used in the spacer-filled channels as well as the transition regions between the entrance or exit sections and the spacer-filled section. Although it is difficult to use cells with same size, the edge length of the cells was fixed to create cells with more homogeneous size distributions. Representative grid systems for parallel-flow and cross-flow spacer-filled modules are shown in Figure 5.

Grid independency analysis was conducted for each simulated module. The pressure drop and transmembrane mass flux of the tested grid systems were compared to determine the appropriate grid sizes. For modules using empty channels, the grid sizes in the length, width and height directions used are $100 \mu \mathrm{m}, 100 \mu \mathrm{m}$ and $20 \mu \mathrm{m}$. For modules using spacer-filled channels, the grid size used is $280 \mu \mathrm{m}$. The total grid numbers of PE-HASMC, PS-HASMC, CE-HASMC and CS-HASMC are 1.08, $1.45,1.33$ and 1.32 million, respectively. 


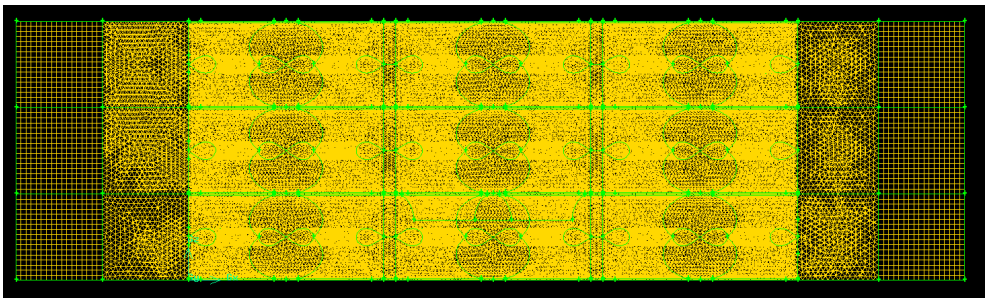

(a)

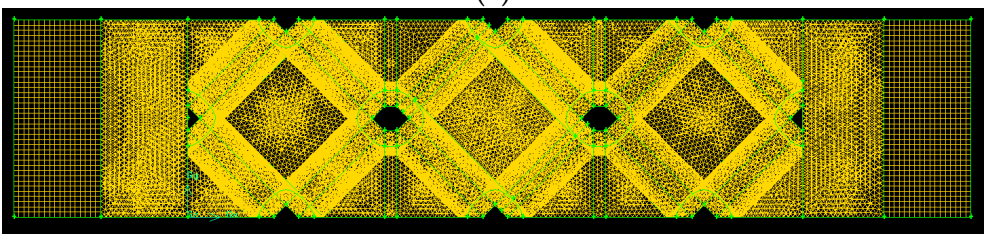

(b)

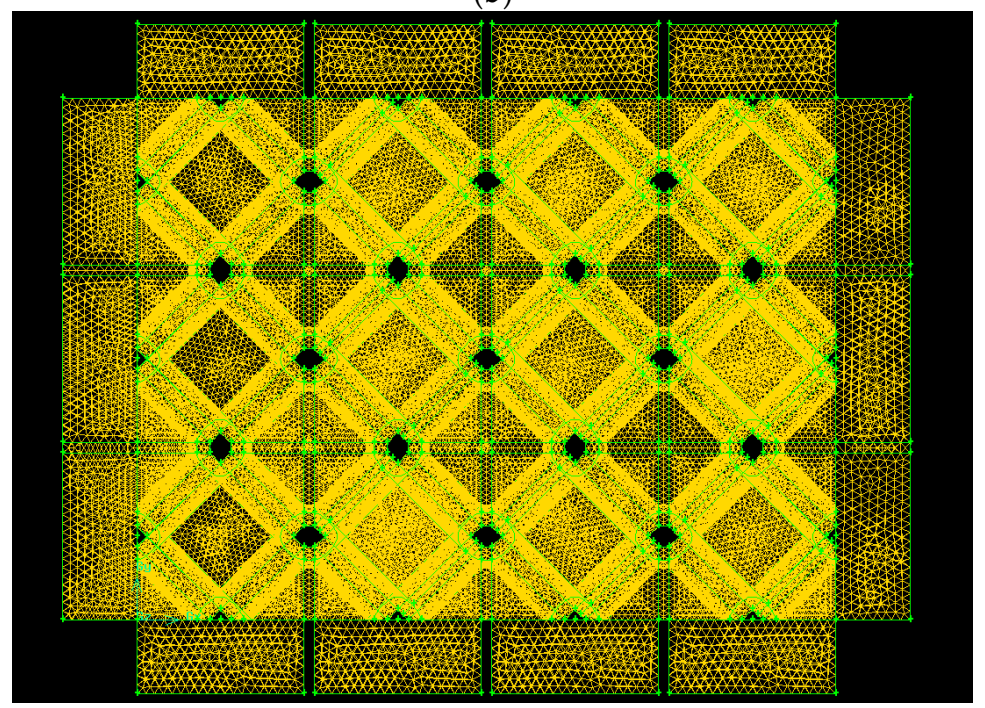

(c)

Figure 5. Computational grid for CFD simulation of HASMCs with spacers (a) parallel-flow (side view), (b) parallel-flow (top view), (c) cross-flow (top view)).

\subsection{Governing Equations}

\subsubsection{Fluid Channels}

For the laminar-flow fluid in each channel, the mass, momentum and energy conservation equations to be solved are described in this section.

The total mass conservation equation with a source term $S_{m}$ is:

$$
\nabla \cdot(\rho \overrightarrow{\mathrm{v}})=\mathrm{S}_{\mathrm{m}}
$$

For a non-reacting system, the mass conservation equation of species $i$ with a source term $S_{i}$ is:

$$
\nabla \cdot\left(\rho \vec{v} y_{i}\right)=-\nabla \cdot \overrightarrow{j_{i}}+S_{i}
$$

where the diffusion flux of species i due to concentration gradients in laminar flow is:

$$
\overrightarrow{j_{i}}=-\rho D_{m, i} \nabla y_{i}
$$


The momentum conservation equation for a system when neglecting the gravitational and external body forces is:

$$
\nabla \cdot(\rho \overrightarrow{\mathrm{v}} \overrightarrow{\mathrm{v}})=-\nabla \mathrm{P}+\nabla \cdot \overline{\bar{\tau}}
$$

where $\overline{\bar{\tau}}$ is the stress tensor:

$$
\overline{\bar{\tau}}=\mu\left[\left(\nabla \overrightarrow{\mathrm{v}}+\nabla \overrightarrow{\mathrm{v}}^{\mathrm{T}}\right)-\frac{2}{3} \nabla \cdot \overrightarrow{\mathrm{v}} \mathrm{I}\right]
$$

The energy conservation equation with a source term $S_{h}$ is:

$$
\nabla \cdot(\vec{v}(\rho \mathrm{E}+\mathrm{P}))=\nabla \cdot\left(\mathrm{k}_{\mathrm{c}} \nabla \mathrm{T}-\sum_{\mathrm{i}} \mathrm{h}_{\mathrm{i}} \overrightarrow{\mathrm{j}_{\mathrm{i}}}+(\overline{\bar{\tau}} \cdot \overrightarrow{\mathrm{v}})\right)+\mathrm{S}_{\mathrm{h}}
$$

where $\mathrm{E}$ is the energy of the flow streams, including the enthalpy, flow work and kinetic energy:

$$
E=\left(\sum_{i} y_{i} h_{i}-\frac{P}{\rho}+\frac{v^{2}}{2}\right)
$$

\subsubsection{Membrane Layer}

In the absorption operation, carbon dioxide will pass across the membrane from the flue gas channel to the absorbent liquid channel. The transmembrane mass flux of carbon dioxide can be determined by the transmembrane pressure difference of carbon dioxide, the membrane average temperature and the membrane permeation coefficient:

$$
\mathrm{N}_{\mathrm{CO}_{2}, \mathrm{abs}}=\frac{\mathrm{k}_{\mathrm{m}}}{\mathrm{RT}_{\mathrm{m}, \mathrm{avg}}} \Delta \mathrm{P}_{\mathrm{CO}_{2}, \mathrm{~m}}=\frac{\mathrm{k}_{\mathrm{m}}}{\mathrm{RT}_{\mathrm{m}, \mathrm{avg}}}\left(\mathrm{P}_{\mathrm{fg}, \mathrm{CO}_{2}, \mathrm{~m}}-\mathrm{P}_{\mathrm{sat}, \mathrm{CO}_{2}, \mathrm{~m}}\right)
$$

The pressure difference is calculated using the carbon dioxide partial pressure of the flue gas cell adjacent to the membrane surface and the saturation carbon dioxide vapor pressure corresponding to the carbon dioxide concentration and temperature of the liquid cell adjacent to the membrane surface.

In the stripping operation, carbon dioxide will pass across the membrane from the absorbent liquid channel to the stripping gas channel. The transmembrane mass flux of carbon dioxide can be determined by the same way as the absorption operation:

$$
\mathrm{N}_{\mathrm{CO}_{2} \text {, strip }}=\frac{\mathrm{k}_{\mathrm{m}}}{\mathrm{RT}_{\mathrm{m}, \mathrm{avg}}} \Delta \mathrm{P}_{\mathrm{CO}_{2}, \mathrm{~m}}=\frac{\mathrm{k}_{\mathrm{m}}}{\mathrm{RT}_{\mathrm{m}, \mathrm{avg}}}\left(\mathrm{P}_{\mathrm{sat}, \mathrm{CO}_{2}, \mathrm{~m}}-\mathrm{P}_{\mathrm{sg}, \mathrm{CO}_{2}, \mathrm{~m}}\right)
$$

The heat flux across the membrane is contributed by the conductive heat transfer across the membrane and the heat flow associated with the transmembrane mass transfer, i.e., the heat of vaporization or condensation of carbon dioxide:

$$
\mathrm{Q}=\mathrm{N}_{\mathrm{CO}_{2}} \Delta \mathrm{H}_{\mathrm{VL}, \mathrm{CO}_{2}}+\frac{\mathrm{k}_{\mathrm{c}, \mathrm{m}}}{\delta_{\mathrm{m}}} \Delta \mathrm{T}_{\mathrm{m}}
$$

The temperatures of the grid cells adjacent to a membrane grid face were used to calculate the transmembrane mass and heat fluxes using Equations (8)-(10). In FLUENT, a user-defined function (UDF) was developed to perform these calculations. The heat and mass fluxes were then defined as an energy source term and a mass source term, respectively, of the grid cells adjacent to the membrane. With this approach, the heat and mass transfer across the membrane can be incorporated into the CFD simulation model.

For physical absorption and stripping, the thermal effect is negligible. The physical and transport properties of carbon dioxide and propylene carbonate were assumed constant, including density, heat capacity, heat of vaporization, viscosity, diffusivity and thermal conductivity. The saturation vapor pressure of carbon dioxide in propylene carbonate solution was calculated using the solubility 
correlation from IUPAC (International Union of Pure and Applied Chemistry) Solubility Data Series [24].

\subsubsection{Boundary Conditions and Solution Algorithms}

The outside walls of the simulated module were defined as adiabatic walls. The outlet faces of all the channels were set as pressure-outlet boundaries with the specified channel pressure values. The inlet faces of all the channels were defined as velocity inlet type boundary with the specified velocity values. In this study, the stripping channels were under vacuum operation instead of using some external stripping gas.

The governing equations were solved using finite volume method and the second-order upwind scheme. A variant of the Semi-Implicit Method for Pressure-Linked Equation (SIMPLEC) algorithm was used to solve the pressure-velocity coupling. The simulation was assumed to have achieved an iterative convergence when the residuals of the mass, momentum and energy conservations equations were less than $1 \times 10^{-5}$ and the transmembrane mass flux does not vary more than $1 \%$ for every 1000 iterations.

\section{Results and Discussion}

\subsection{Model Verification}

The model was verified using the experimental data from [25]. The experimental device is a hollow fiber module for absorbing carbon dioxide from a nitrogen-carbon dioxide gas mixture using propylene carbonate. The simulated system is shown in Figure 6a for only a 30 degree segment. The membrane used was an Accurel Q3/2 Polypropylene membrane.

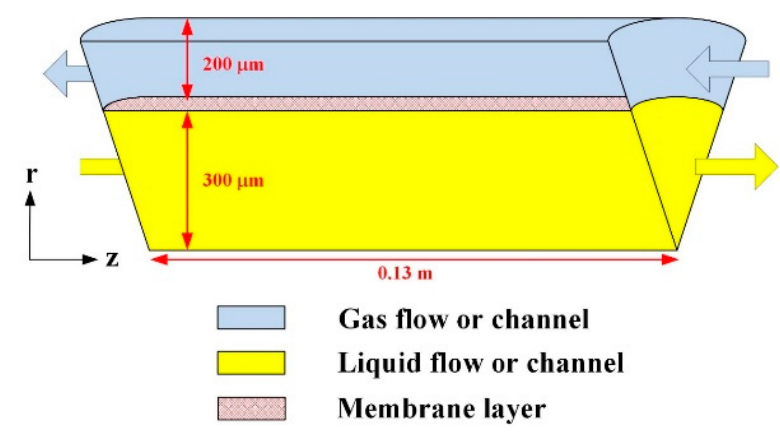

(a)

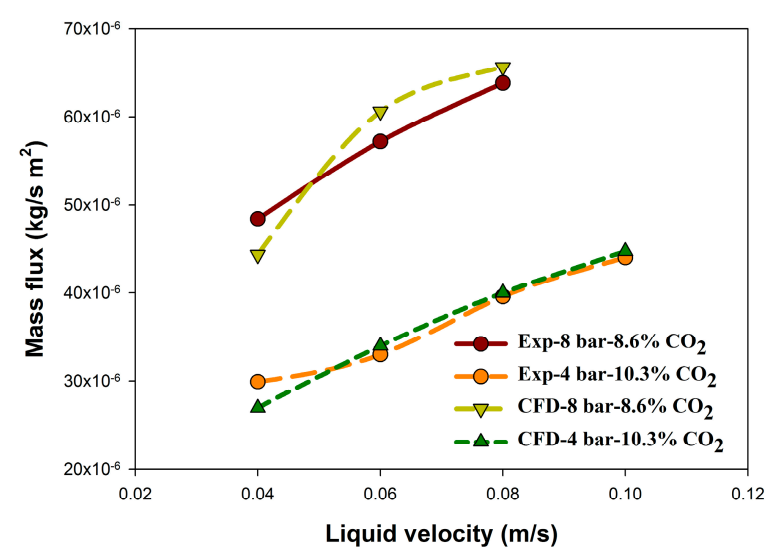

(b)

Figure 6. Model verification using experimental data from [25]: (a) simulation system; (b) comparison of simulated and experimental transmembrane $\mathrm{CO}_{2}$ mass flux. 
The mass fluxes of carbon dioxide from CFD simulated and experimental are compared in Figure $6 \mathrm{~b}$ for two operation conditions, i.e., 8 bar with the gas containing $8.6 \% \mathrm{CO}_{2}$ and 4 bar with the gas containing $10.3 \% \mathrm{CO}_{2}$. The results are fairly close.

\subsection{Parallel-Flow HASMC}

The common operation conditions for all simulation cases of parallel-flow modules are: (1) the pressures of flue gas and absorbent liquid channels are both 1 bar, (2) the pressure of stripping channel is 0.04 bar, (3) the temperatures of all channels are $298 \mathrm{~K}$, (4) the concentration of carbon dioxide in the inlet flue gas is $15 \mathrm{~mol} \%$. Other operation conditions of the simulated cases for parallel-flow modules are listed in Table 1.

Table 1. Simulated cases for parallel-flow HASMC.

\begin{tabular}{ccc}
\hline Operation Conditions & BC & Case 1 \\
\hline Gas inlet velocity $(\mathrm{m} / \mathrm{s})$ & 0.018 & 0.018 \\
Liquid inlet velocity $(\mathrm{m} / \mathrm{s})$ & 0.02 & 0.02 \\
Liquid inlet concentration $(\mathrm{mol} \%)$ & 0.13 (empty) & \\
Liquid diffusivity $\left(\mathrm{m}^{2} / \mathrm{s}\right)$ & 0.06 (spacer-filled) & \\
\hline
\end{tabular}

For the BC of PE-HASMC, the liquid channel carbon dioxide concentration profiles are shown in Figure 7. The absorption and stripping concentration boundary layers are independent and separated by the bulk liquid. With this characteristic, PE-HASMC cannot provide the anticipated effect of enhancement of the absorption and stripping mass transfer by simultaneous absorption and stripping within one module.

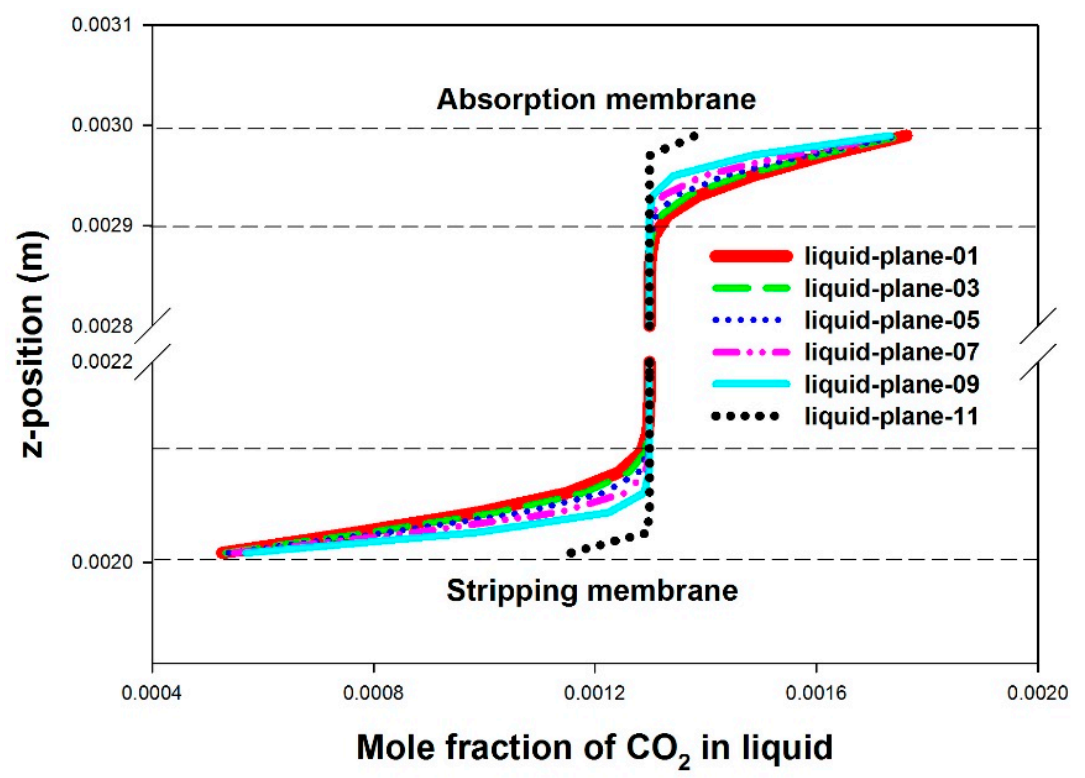

Figure 7. PE-HASMC $\mathrm{CO}_{2}$ concentration profiles in liquid channel (BC, liquid entry at $x=0.02 \mathrm{~m}$ and liquid-plane-11).

For the BC of PS-HASMC, the fluctuating patterns, which corresponds to the spacer configuration, of the absorption and stripping fluxes are shown in Figure 8a. The concentration profiles inside the liquid channels (Case 1, higher liquid diffusivity) shown in Figure $8 \mathrm{~b}$ are remarkably different from that shown in Figure 7. Because of the eddy promoting effect of spacers, the concentration boundary layers are not limited to a small thickness. The carbon dioxide can be conveyed from the absorption membrane through the depth of the liquid into the other side, i.e., the stripping membrane. 


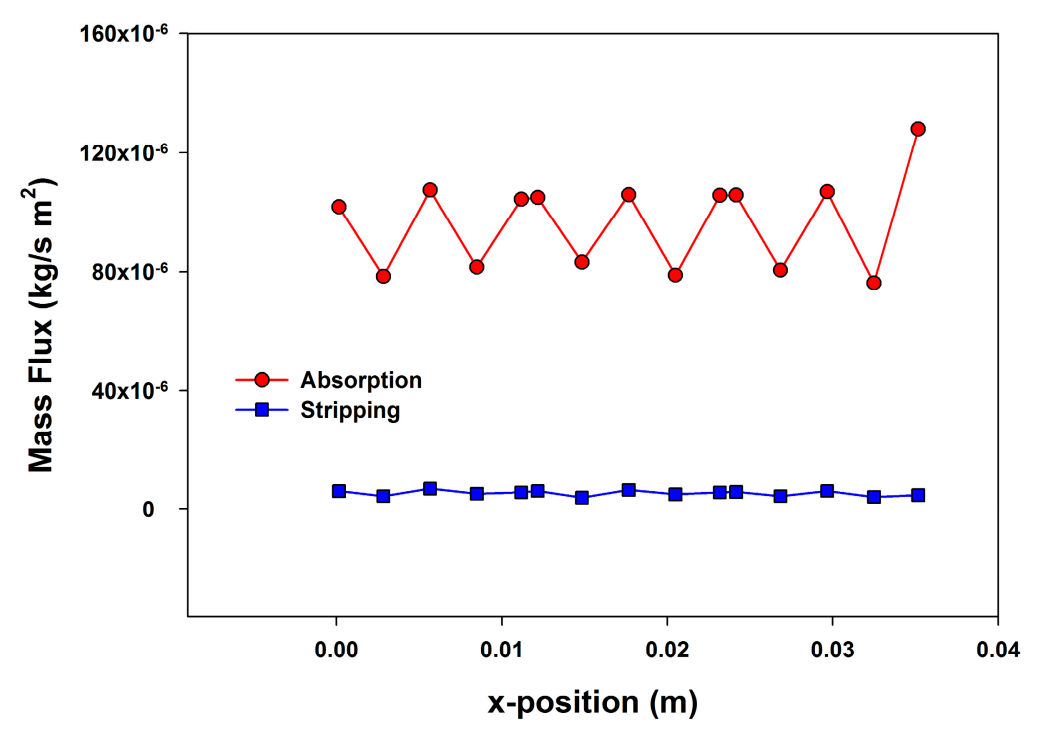

(a)

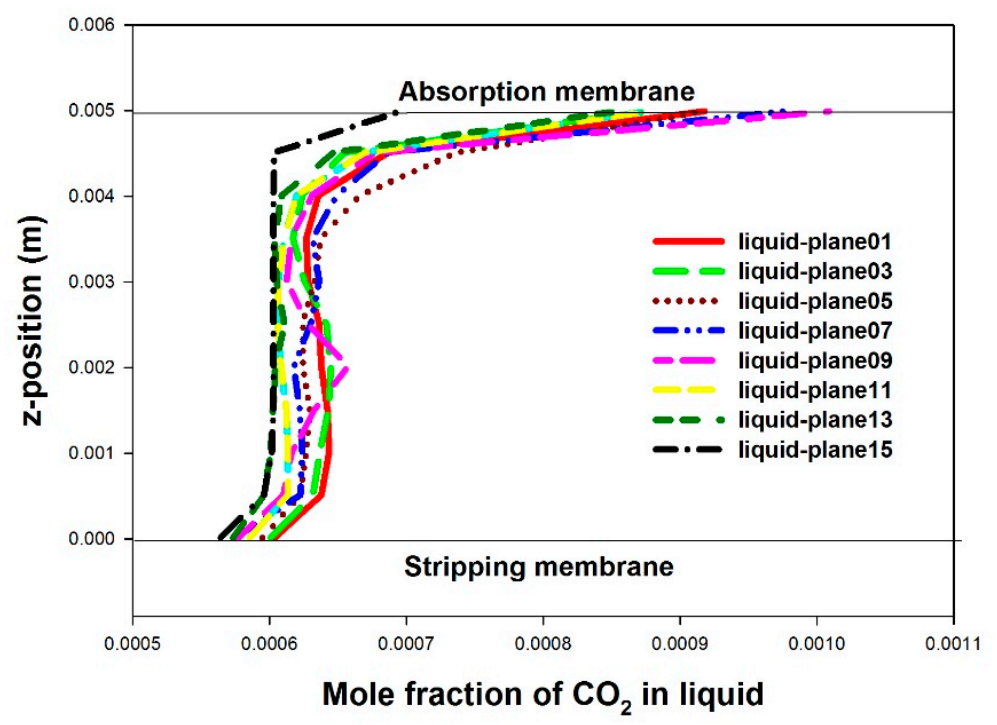

(b)

Figure 8. PS-HASMC internal profiles ((a) transmembrane $\mathrm{CO}_{2}$ mass flux (BC), (b) $\mathrm{CO}_{2}$ concentration profiles in liquid channel) (Case 1, liquid entrance at liquid-plane-15).

\subsection{Cross-Flow HASMC}

The common operation conditions for all simulation cases of cross-flow modules are: (1) the pressures of flue gas and absorbent liquid channels are both 1 bar, (2) the pressure of stripping channel is 0.04 bar, (3) the temperatures of all channels are $298 \mathrm{~K}$, (4) the concentration of carbon dioxide in the inlet flue gas is $15 \mathrm{~mol} \%$. Other operation conditions of the simulated cases for cross-flow modules are listed in Table 2.

For the $\mathrm{BC}$ of CE-HASMC, the transmembrane $\mathrm{CO}_{2}$ mass fluxes for the two absorption sections and two stripping sections are shown in Figure 9a. Note that the stripping mass flux is presented by negative value in this figure. For each of the four channels, affected by the liquid concentration change after absorption or stripping, the mass flux decreases along the flow direction of liquid ( $x$-direction). For both absorption and stripping, the fluxes of the first and the second channels are close. This result indicates the cross-flow module can effectively refresh the liquid for the second absorption following the first stripping. 
Table 2. Simulated cases for cross-flow HASMC.

\begin{tabular}{cccc}
\hline Simulation Conditions & BC & Cases 1-3 & Case 4 \\
\hline Gas inlet velocity $(\mathrm{m} / \mathrm{s})$ & 0.06 & 0.06 & 0.06 \\
\hline Liquid inlet velocity $(\mathrm{m} / \mathrm{s})$ & 0.01 & $0.005 / 0.02 / 0.04$ & 0.01 \\
\hline & 0.15 (empty) & 0.15 (empty) & 0.15 (empty) \\
Liquid inlet concentration $(\mathrm{mol} \%)$ & 0.06 & 0.06 & 0.06 \\
& $($ spacer-filled) & (spacer-filled) & (spacer-filled) \\
\hline Liquid diffusivity $\left(\mathrm{m}^{2} / \mathrm{s}\right)$ & $1 \times 10^{-9}$ & $1 \times 10^{-9}$ & $1 \times 10^{-8}$ \\
\hline
\end{tabular}

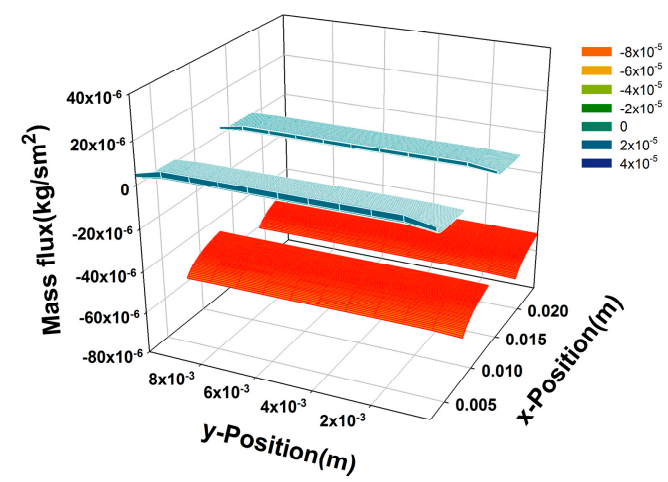

(a)

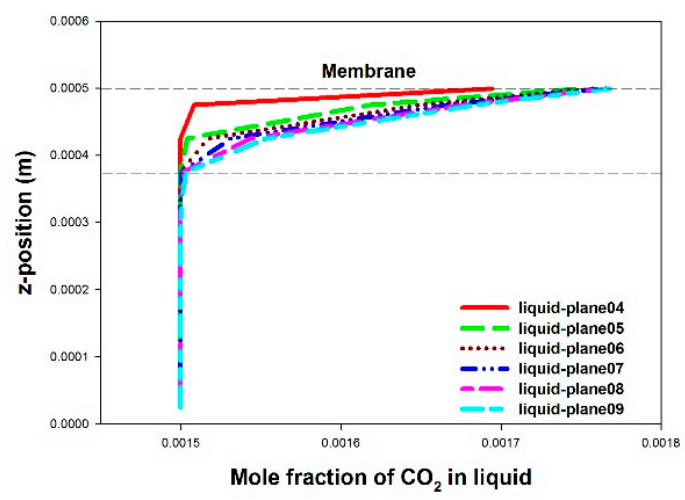

(c)

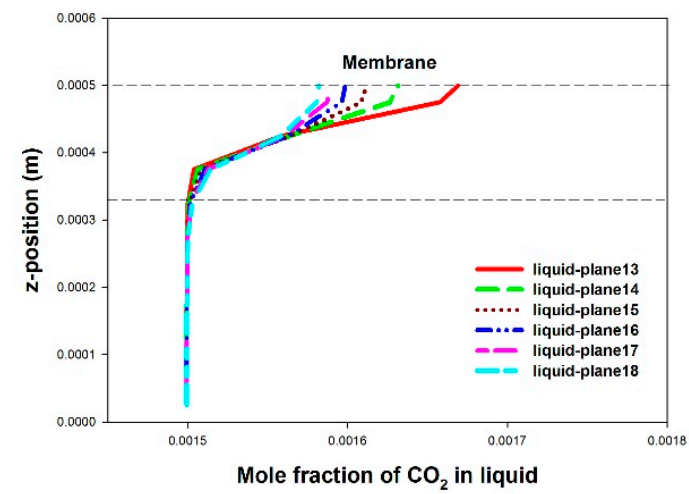

(e)

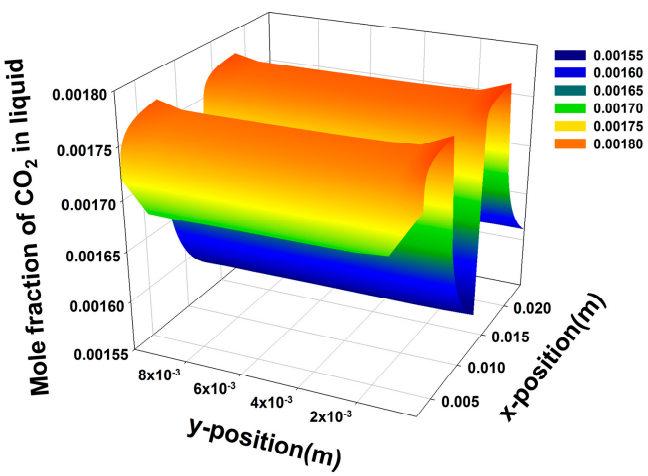

(b)

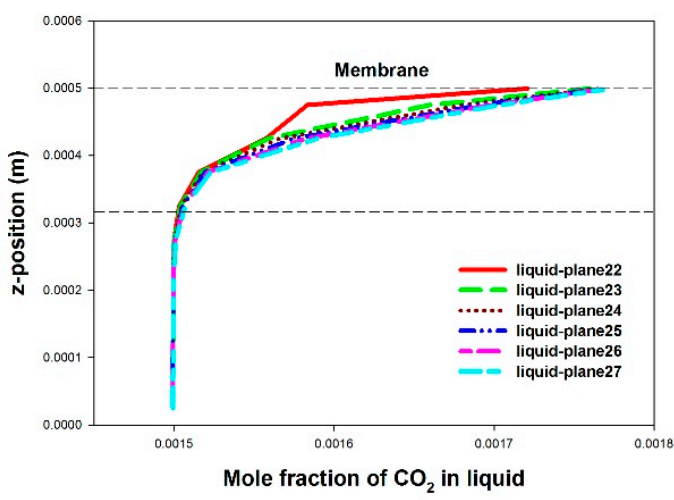

(d)

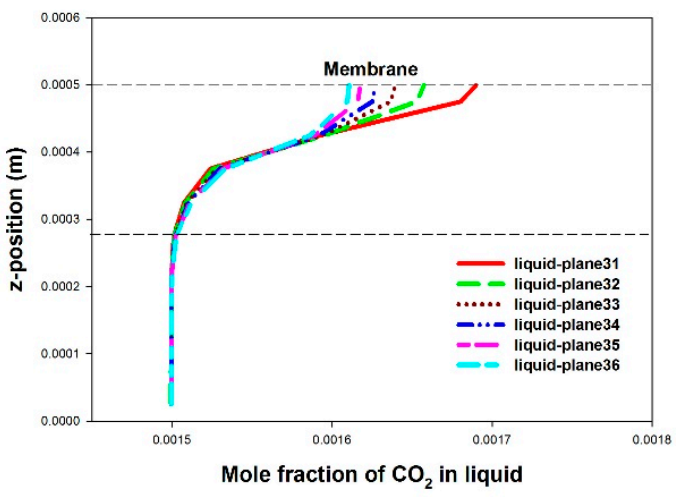

(f)

Figure 9. CE-HASMC BC internal profiles ((a) transmembrane $\mathrm{CO}_{2}$ mass flux, (b) membrane surface liquid $\mathrm{CO}_{2}$ concentration, (c) first absorber (liquid entry: liquid-plane04), (d) second absorber (liquid entry: liquid-plane22), (e) first stripper (liquid entry: liquid-plane13), (f) second stripper (liquid entry: liquid-plane31), (c-f) $\mathrm{CO}_{2}$ concentration profiles in liquid channel). 
The profile of liquid concentration at membrane surface, as shown in Figure $9 b$, reveals the concentration increase in each absorption section and the concentration decrease in each stripping section along the liquid flow direction. The internal concentration profiles of the liquid are revealed in Figure 9c-f. For both absorption and stripping, the thickness of the concentration boundary layer of the second section is greater than of the first one. The effects of liquid velocity and the liquid diffusivity on mass flux are shown in Figure 10. Note that the stripping flux is presented as positive value in this figure. Comparing $B C$ and Cases 1-3, the higher the liquid velocity, the higher the absorption flux because the concentration can be maintained at lower levels. However, the effect of liquid velocity on the stripping flux is reversed because of the same reason. Comparing BC and Case 4, raising the liquid diffusivity by ten times (Case 4) can significantly increase the absorption flux and decrease the stripping flux. Both effects are caused by the lower membrane surface concentration due to higher diffusivity.

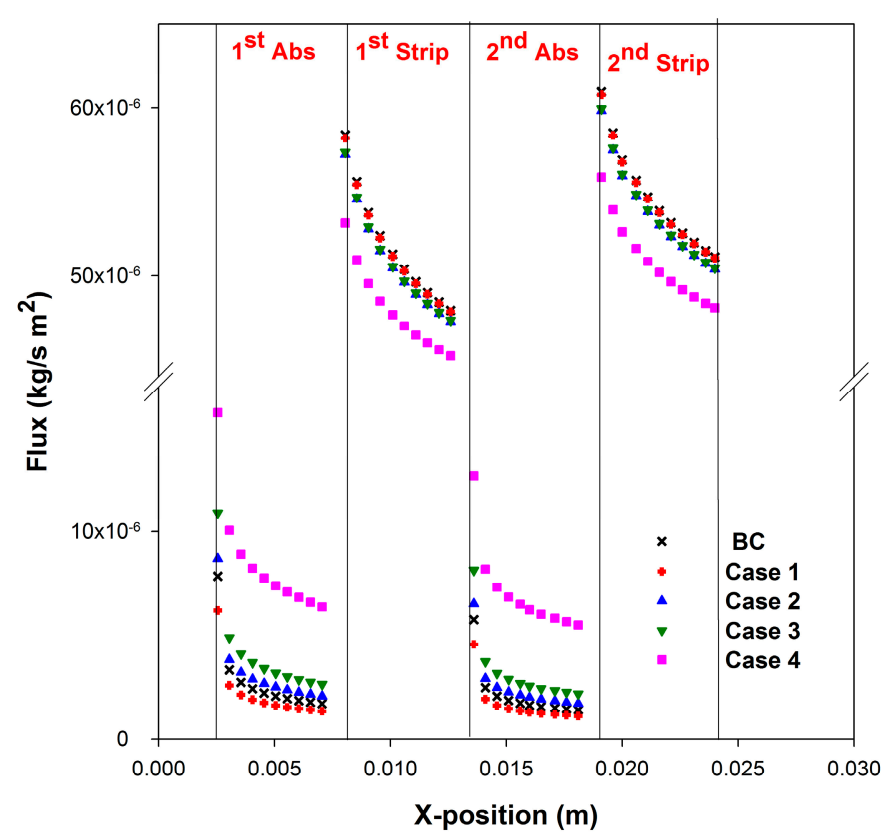

Figure 10. Effects of liquid velocity and diffusivity on transmembrane $\mathrm{CO}_{2}$ mass flux in CE-HASMC.

For the BC of CS-HASMC, the mass fluxes in the liquid flow direction, shown in Figure 11a, vary in a fluctuating pattern corresponding to the spacer configuration. The stripping fluxes are higher than the absorption fluxes. Both absorption and stripping fluxes decrease along the flow direction but the change of the stripping flux is more significant. These outcomes are due to the higher mass transfer driving force in the stripping operation. The variations of liquid concentration at membrane surface in the liquid flow direction, as shown in Figure 11b, are similar to the profiles shown in Figure 11a.

The internal liquid concentration profiles are revealed in Figure 11c-f. The profiles are similar to that of CE-HASMC shown in Figure 9. However, aided by the eddy-promoting effect of spacers, the thicknesses of concentration boundary layer of the first and the second sections are about the same for both absorption and stripping.

For CS-HASMC, the effects of liquid velocity and the liquid diffusivity on mass flux, as shown in Figure 12, are similar to that of CE-HASMC. Comparing BC and Cases 1-3, the higher the liquid velocity, the higher the absorption flux because the liquid concentration can be maintained at lower level. However, the effect of liquid velocity on the stripping flux is reversed because of the lower liquid concentration. Unlike in CE-HASMC, comparing BC and Case 4, the increase of mass flux by raising the liquid diffusivity by ten times (Case 4 ) is limited. This is because the use of spaces has provided substantial enhancement of diffusion effect. 


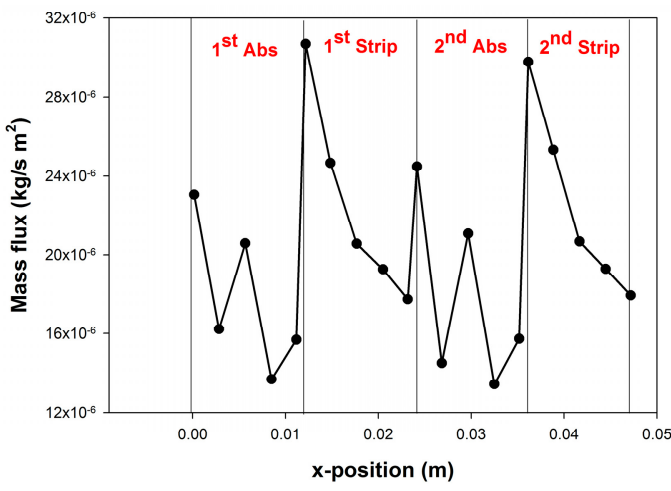

(a)

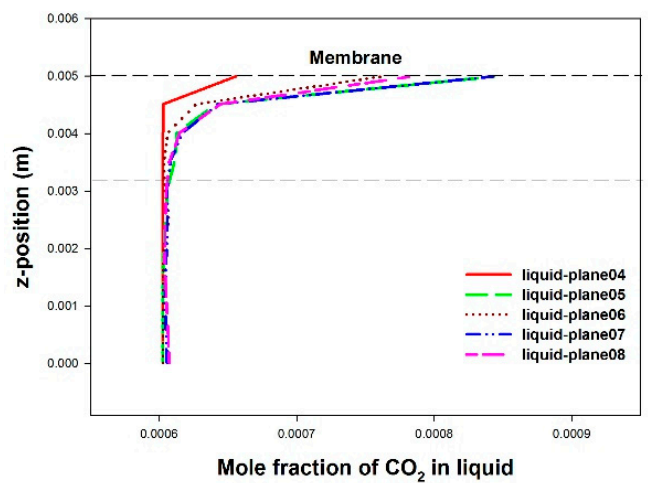

(c)

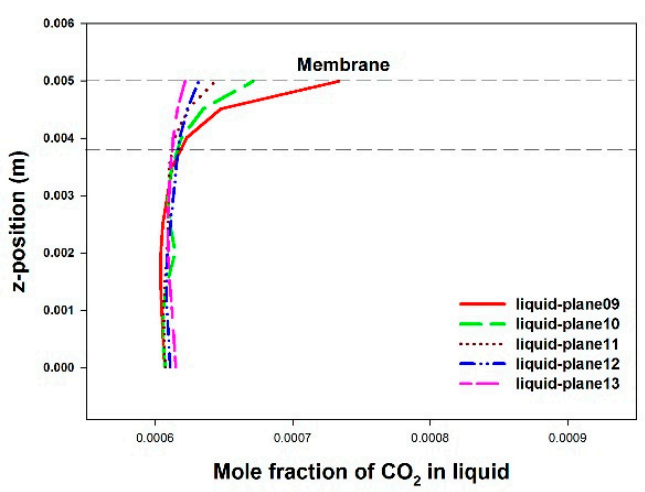

(e)

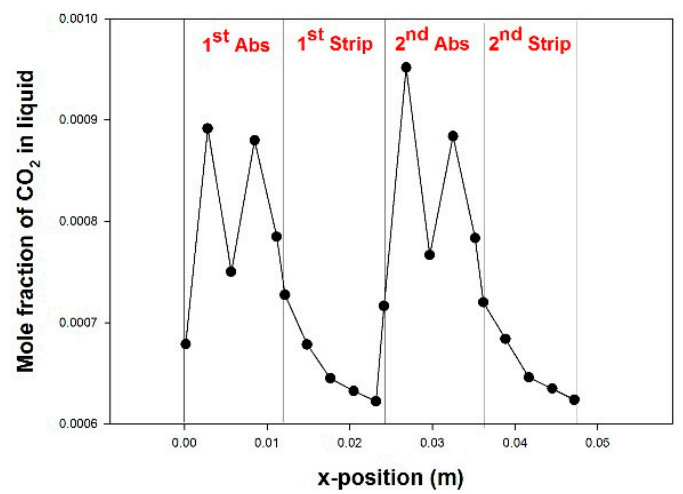

(b)

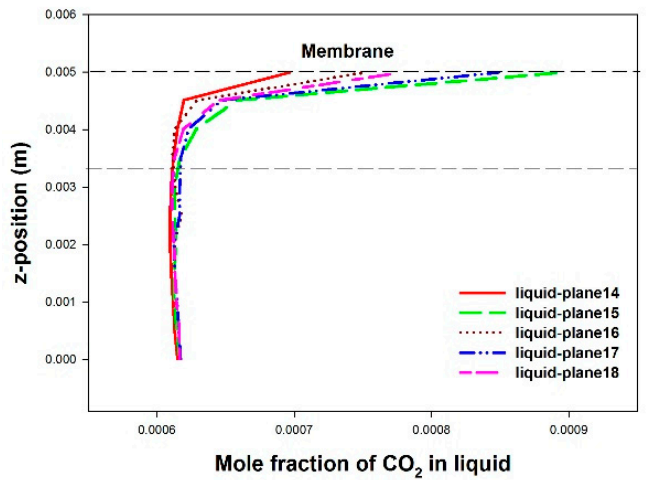

(d)

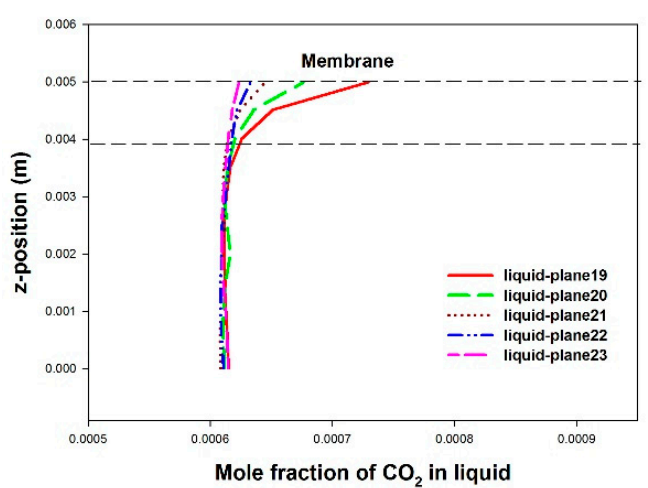

$(\mathbf{f})$

Figure 11. CS-HASMC BC internal profiles ((a) transmembrane $\mathrm{CO}_{2}$ mass flux, (b) membrane surface liquid $\mathrm{CO}_{2}$ concentration, (c) first absorber, (liquid entry: liquid-plane04), (d) second absorber (liquid entry: liquid-plane14), (e) first stripper (liquid entry: liquid-plane09), (f) second stripper (liquid entry: liquid-plane19), (c-f) $\mathrm{CO}_{2}$ concentration profiles in liquid channel).

For both CE-HASMC and CS-HASMC, the results presented above have demonstrated that the mass fluxes of the first and the second absorption sections as well as that of the first and the second stripping sections can be maintained at about the same level. Hence, a remark can be made that cross-flow is an effective configuration to achieve the objective of HASMC. 


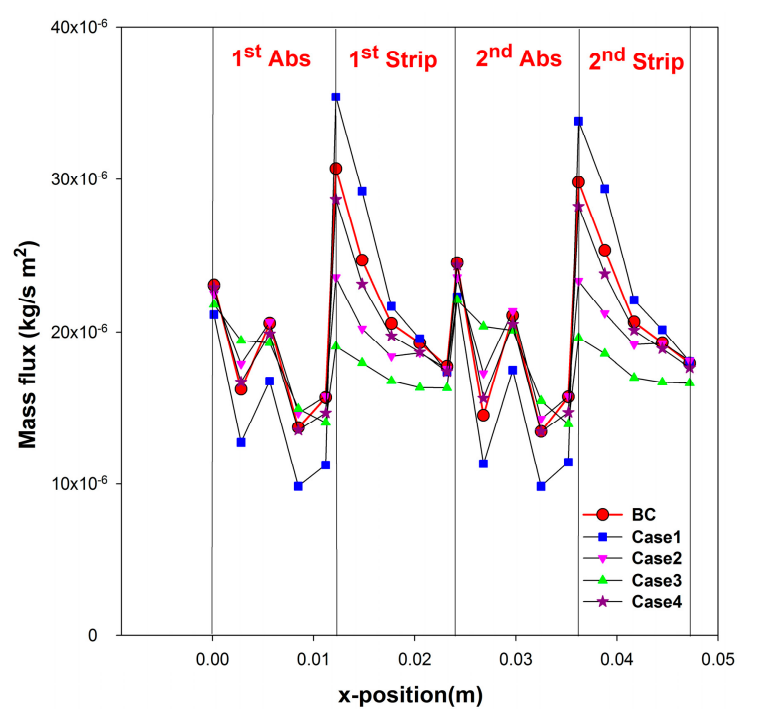

Figure 12. Effect of liquid velocity and diffusivity on mass flux in CS-HASMC (at $y=$ midpoint).

\subsection{Transfer Coefficients}

The performance of membrane contactors can be expressed by the heat or mass transfer coefficient. For CS-HASMC, this study determined the liquid mass transfer coefficients from the CFD simulation results and compared them with the correlations for spacer-filled channels reported in the literature.

The mass transfer coefficient can be determined using the transmembrane mass flux, the average bulk liquid concentration and the membrane surface concentration (concentration of the cell adjacent to the membrane) by:

$$
\mathrm{k}_{\mathrm{L}}=\mathrm{N} /\left(\mathrm{C}_{\mathrm{L}, \text { bulk }}-\mathrm{C}_{\mathrm{L}, \mathrm{m}}\right)
$$

For comparison with correlations from literature, Sherwood number (Sh) was used. Sh is defined as:

$$
\mathrm{Sh}_{\mathrm{L}}=\frac{\mathrm{k}_{\mathrm{L}} \mathrm{d}_{\mathrm{h}}}{\mathrm{D}_{\mathrm{L}}}
$$

The local $\mathrm{Sh}_{\mathrm{L}}$ inside CS-HASMC for BC is shown in Figure 13. Similar to the mass flux and liquid concentration profiles presented in Figures 9 and 11, fluctuating patterns are observed in the two absorption sections and monotonic variations are shown in the two stripping sections. The results indicate that: (1) the local Sherwood numbers are not constant inside a module, (2) the Sherwood numbers vary with concentration, and (3) the Sherwood numbers of absorption and stripping sections are quite different.

The correlations from literature for comparison with the simulation results from this study are listed in Table 3. All correlations are all for spacer-filled channels. Correlations $\{1\}-\{4\}$ were developed by Koutsou et al. [26] using the mass transfer experimental results of electrolyte solutions. Correlation \{5\} was developed by Da Costa et al. [27] for the mass transfer in ultrafiltration modules. Correlation $\{6\}$ was developed by Chang et al. [19] for the heat transfer coefficients in the membrane distillation modules and was converted into correlations for mass transfer coefficients via Chilton-Colburn analogy [28]. As shown in Figure 13, the mass transfer coefficients of the HASMC are much higher than the predictions from these correlations. 


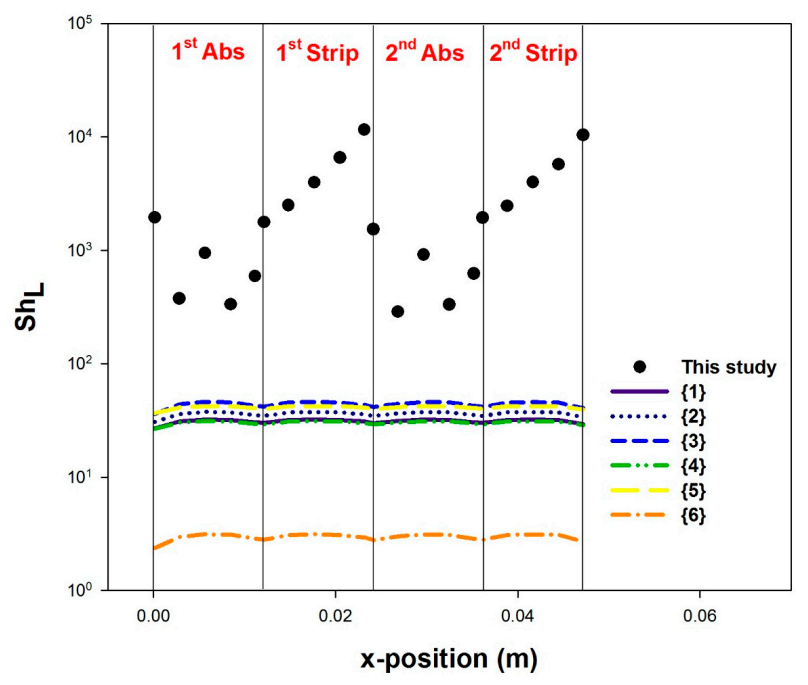

Figure 13. Liquid channel local Sherwood number of CS-HASMC (BC).

Table 3. Mass transfer correlations for spacer-filled channels.

\begin{tabular}{ccc}
\hline No. & Correlations & References \\
\hline$\{1\}$ & $\mathrm{Sh}=0.14 \operatorname{Re}^{0.64} \mathrm{Sc}^{0.42} \mathrm{~L}_{\mathrm{m}} / \mathrm{D}_{\mathrm{f}}=6 ; \theta=90^{\circ}$ & {$[26]$} \\
$\{2\}$ & $\mathrm{Sh}=0.16 \mathrm{Re}^{0.605} \mathrm{Sc}^{0.42} \mathrm{~L}_{\mathrm{m}} / \mathrm{D}_{\mathrm{f}}=8 ; \theta=90^{\circ}$ & {$[26]$} \\
$\{3\}$ & $\mathrm{Sh}=0.26 \operatorname{Re}^{0.57} \mathrm{Sc}^{0.37} \mathrm{~L}_{\mathrm{m}} / \mathrm{D}_{\mathrm{f}}=12 ; \theta=90^{\circ}$ & {$[26]$} \\
$\{4\}$ & $\mathrm{Sh}=0.2 \operatorname{Re}^{0.57} \mathrm{Sc}^{0.4} \mathrm{~L}_{\mathrm{m}} / \mathrm{D}_{\mathrm{f}}=8$ and $12 ; \theta=90^{\circ}$ & {$[26]$} \\
$\{5\}$ & $\mathrm{Sh}=0.664 \mathrm{k}_{\mathrm{dc}}(\operatorname{Re})^{0.5} \mathrm{Sc}^{0.33}\left(\frac{2 \mathrm{D}_{\mathrm{h}}}{\mathrm{L}_{\mathrm{m}}}\right)^{0.5}$ where $\mathrm{k}_{\mathrm{dc}}=1.654\left(\frac{\mathrm{D}_{\mathrm{f}}}{\mathrm{H}}\right)^{-0.039}{ }_{\varepsilon^{0.75}\left(\sin \left(\frac{\theta}{2}\right)\right)^{0.086}}$ & {$[27]$} \\
$\{6\}$ & $\mathrm{Sh}=0.1 \operatorname{Re} \mathrm{L}_{\mathrm{m}} / \mathrm{D}_{\mathrm{f}}=8 ; \theta=90^{\circ}$ & {$[19]$} \\
\hline
\end{tabular}

\section{Conclusions}

A rigorous CFD simulation has been implemented for the four types of the hybrid absorption and stripping membrane contactors proposed by the authors to examine their performance for carbon dioxide capture using the physical solvent propylene carbonate.

The parallel configuration with empty channels, PE-HASMC module, does not provide the anticipated enhancement of absorption. The reason is that the concentration boundary layers of absorption and stripping are far away from each other. However, by employing spacer-filled channels, i.e., PS-HASMC, the absorbed carbon dioxide can be conveyed from the absorption membrane across the depth of liquid channel to the stripping membrane. Therefore, some degree of performance enhancement can be obtained.

The two types of HASMC with cross-flow configuration and interlaced arrangement of absorption and stripping sections, i.e., CE-HASMC and CS-HASMC, can provide significant performance enhancements. The performance enhancement is realized via refreshing the liquid by the stripping operation following the absorption section within the same module. In both CE-HASMC and CS-HASMC, about the same mass fluxes in the first and the second absorption sections can be obtained. The same holds for the stripping. For CE-HASMC, the increase of liquid diffusivity can result in higher mass flux. However, because the mass transfer enhancement by spacers is significant, the effect of liquid diffusivity is insignificant for CS-HASMC. The mass transfer coefficients of the absorption section and the stripping section in the CS-HASMC are significantly different. The mass transfer coefficients of both absorption and stripping sections are much higher than the predictions from correlations for spacer-filled channels in the literature.

The authors are currently carrying out experimental work using plate-type membrane modules including parallel-flow and cross-flow configurations with both empty and spacer-filled channels to verify the performance of HASMC. 
Acknowledgments: The authors gratefully acknowledge the sponsorship from the Ministry of Science and Technology of Taiwan.

Author Contributions: This paper is a result of the full collaboration of all the authors. Hsuan Chang conceived the concept of the novel device; Hau-Yu Gan performed the simulation; Yih-Hang Chen analyzed the simulation results; Hsuan Chang and Chii-Dong Ho elaborated the manuscript preparation.

Conflicts of Interest: The authors declare no conflict of interest.

\section{Nomenclature}

\begin{tabular}{|c|c|}
\hline $\mathrm{BC}$ & base case \\
\hline $\mathrm{C}$ & concentration $\left(\mathrm{kmol} / \mathrm{m}^{3}\right)$ \\
\hline CE & cross-flow configuration with empty channels \\
\hline CS & cross-flow configuration with spacer-filled channels \\
\hline$d_{h}$ & hydraulic diameter $(\mathrm{m})$ \\
\hline $\mathrm{D}_{\mathrm{f}}$ & diameter of filament $(\mathrm{m})$ \\
\hline $\mathrm{D}$ & molecular diffusivity $\left(\mathrm{m}^{2} / \mathrm{s}\right)$ \\
\hline $\mathrm{E}$ & specific total energy $(\mathrm{J} / \mathrm{kg})$ \\
\hline $\mathrm{h}$ & heat transfer coefficient $\left(\mathrm{W} / \mathrm{m}^{2} \mathrm{~K}\right)$ or specific enthalpy $(\mathrm{J} / \mathrm{kg})$ \\
\hline $\mathrm{H}$ & height of spacer $(\mathrm{m})$ \\
\hline $\mathrm{H}_{\mathrm{VL}}$ & specific enthalpy of vaporization $(\mathrm{J} / \mathrm{kg})$ \\
\hline HASMC & hybrid absorption and stripping membrane contactor \\
\hline I & unit matrix \\
\hline $\mathrm{j}_{\mathrm{i}}$ & diffusion flux of species i $\left(\mathrm{kg} / \mathrm{m}^{2} \mathrm{~s}\right)$ \\
\hline $\mathrm{k}_{\mathrm{c}}$ & thermal conductivity $\left(\mathrm{kg} / \mathrm{m}^{2} \mathrm{~s}\right)$ \\
\hline $\mathrm{k}_{\mathrm{L}}$ & mass transfer coefficient in the liquid $(\mathrm{m} / \mathrm{s})$ \\
\hline $\mathrm{k}_{\mathrm{m}}$ & mass transfer coefficient in the membrane $(\mathrm{m} / \mathrm{s})$ \\
\hline $\mathrm{L}_{\mathrm{m}}$ & filament mesh size $(\mathrm{m})$ \\
\hline $\mathrm{N}$ & $\operatorname{mass}$ flux $\left(\mathrm{kg} / \mathrm{m}^{2} \mathrm{~s}\right)$ \\
\hline $\mathrm{P}$ & Pressure $(\mathrm{Pa})$ \\
\hline PE & parallel-flow configuration with empty channel \\
\hline PS & parallel-flow configuration with spacer-filled channel \\
\hline Q & heat flux $\left(\mathrm{W} / \mathrm{m}^{2}\right)$ \\
\hline $\mathrm{R}$ & gas constant $(\mathrm{J} /$ mole $\mathrm{K})$ \\
\hline $\operatorname{Re}$ & Reynolds number, $\frac{\rho \mathrm{u}_{\mathrm{m}} \mathrm{d}_{\mathrm{h}}}{\mu}$ \\
\hline Sc & Schmidt number, $\frac{\mu}{\rho \mathrm{D}}$ \\
\hline Sh & Sherwood number, $\frac{\mathrm{kd}_{\mathrm{h}}}{\mathrm{D}}$ \\
\hline$S_{\mathrm{h}}$ & energy source term $\left(\mathrm{kJ} / \mathrm{m}^{3} \mathrm{~s}\right)$ \\
\hline$S_{i}$ & mass source term of species $\mathrm{i}\left(\mathrm{kg} / \mathrm{m}^{3} \mathrm{~s}\right)$ \\
\hline$S_{m}$ & mass source term of mixture $\left(\mathrm{kg} / \mathrm{m}^{3} \mathrm{~s}\right)$ \\
\hline $\mathrm{T}$ & temperature $(\mathrm{K})$ \\
\hline $\mathrm{T}_{\mathrm{m}}$ & membrane mean temperature $(\mathrm{K})$ \\
\hline $\mathrm{v}$ & velocity $(\mathrm{m} / \mathrm{s})$ \\
\hline$y_{i}$ & mass fraction of species i \\
\hline
\end{tabular}

\section{Greek Letters}

membrane thickness (m)

membrane porosity or spacer porosity

hydrodynamic angles (degree)

viscosity (Pa s)

density $\left(\mathrm{kg} / \mathrm{m}^{3}\right)$

tortuosity or stress tensor $(\mathrm{Pa} / \mathrm{m})$ 


\section{Subscript}

$\begin{array}{ll}\text { abs } & \text { absorption } \\ \text { avg } & \text { average } \\ \text { bulk } & \text { bulk fluid } \\ \mathrm{fg} & \text { flue gas } \\ \mathrm{i} & \text { species i } \\ \mathrm{L} & \text { liquid } \\ \mathrm{m} & \text { membrane } \\ \text { sat } & \text { saturation } \\ \text { sg } & \text { stripping gas } \\ \text { strip } & \text { stripping }\end{array}$

\section{References}

1. Global CCS Institute. The Global Status of CCS, February 2014; Global CCS Institute: Tokyo, Japan, 2014.

2. National Energy Technology Laboratory. Research and Development Goals for $\mathrm{CO}_{2}$ Capture, DOE/NETL2009/1366; U.S. Department of Energy: South Park Township, PA, USA, 2011.

3. Kohl, A.L.; Nielsen, R.B. Gas Purification, 5th ed.; Gulf Publishing Company: Houston, TX, USA, 1997; pp. 1188-1190, 1187-1237, ISBN 0884152200.

4. Drioli, E.; Criscuoli, A.; Curcio, E. Membrane Contactors: Fundamentals, Applications and Potentialities; Elsevier Science: Amsterdam, The Netherlands, 2005; pp. 5-39, ISBN 9780444522030.

5. Reed, B.W.; Semmens, M.J.; Cussler, E.L. Membrane Contactors, Membrane Separation Technology, Principles and Applications; Elsevier Science: Amsterdam, The Netherlands, 1995; pp. 467-498, ISBN 9780444816337.

6. Al-Marzouqi, M.H.; Marzouk, S.A.M.; El-Naas, M.H.; Abdullatif, N. $\mathrm{CO}_{2}$ removal from $\mathrm{CO}_{2}-\mathrm{CH}_{4}$ gas mixture using different solvents and hollow fiber membranes. Ind. Eng. Chem. Res. 2009, 48, 3600-3605. [CrossRef]

7. Mansourizadeh, A.; Ismail, A.F.; Matsuura, T. Effect of operating conditions on the physical and chemical $\mathrm{CO}_{2}$ absorption through the PVDF hollow fiber membrane contactor. J. Membr. Sci. 2010, 353, 192-200. [CrossRef]

8. Simioni, M.; Kentish, S.E.; Stevens, G.W. Membrane stripping: Desorption of carbon dioxide from alkali solvents. J. Membr. Sci. 2011, 378, 18-27. [CrossRef]

9. Lu, J.G.; Hua, A.C.; Xu, Z.W.; Li, J.T.; Liu, S.Y.; Wang, Z.L.; Zhao, Y.L.; Pan, C. $\mathrm{CO}_{2}$ capture by membrane absorption coupling process: Experiments and coupling process evaluation. J. Membr. Sci. 2013, 431, 9-18. [CrossRef]

10. Kreulen, H.; Smolders, C.A.; Versteeg, G.F.; van Swaaij, W.P.M. Microporous follow fibre membrane modules as gas-liquid contactors, Part 1. Physical mass transfer processes. J. Membr. Sci. 1993, 78, 197-216. [CrossRef]

11. Kreulen, H.; Smolders, C.A.; Versteeg, G.F.; van Swaaij, W.P.M. Microporous follow fibre membrane modules as gas-liquid contactors, Part 2. Mass transfer with chemical reaction. J. Membr. Sci. 1993, 78, 217-238. [CrossRef]

12. Hoff, K.A.; Svendsen, H.F. Membrane contactors for $\mathrm{CO}_{2}$ absorption-Application, modeling and mass transfer effects. Chem. Eng. Sci. 2014, 116, 331-341. [CrossRef]

13. Goyal, N.; Suman, S.; Gupta, S.K. Mathematical modeling of $\mathrm{CO}_{2}$ separation from gaseous-mixture using a hollow-fiber membrane module: Physical mechanism and influence of partial-wetting. J. Membr. Sci. 2015, 474, 64-82. [CrossRef]

14. Yang, X.; Yu, H.; Wang, R.; Fane, A.G. Optimization of microstructured hollow fiber design for membrane distillation applications using CFD modeling. J. Membr. Sci. 2012, 421, 258-270. [CrossRef]

15. Ho, C.D.; Chang, H.; Chang, C.L.; Huang, C.H. Theoretical and experimental studies of performance enhancement with roughened surface in direct contact membrane distillation desalination. J. Membr. Sci. 2013, 433, 160-166. [CrossRef]

16. Martínez, L.; Vázquez-González, M.I.; Florido-Díaz, F.J. Study of membrane distillation using channel spacers. J. Membr. Sci. 1998, 144, 45-56. [CrossRef]

17. Phattaranawik, J.; Jiraratananon, R.; Fane, A.G.; Halim, C. Mass flux enhancement using spacer filled channel in direct contact membrane distillation. J. Membr. Sci. 2001, 187, 93-201. [CrossRef] 
18. Shakaib, M.; Hasani, S.M.F.; Ahmed, I.; Yunus, R.M. A CFD study on the effect of spacer orientation on polarization in membrane distillation modules. Desalination 2012, 284, 332-340. [CrossRef]

19. Chang, H.; Hsu, J.A.; Chang, C.L.; Ho, C.D.; Cheng, T.W. Simulation study of transfer characteristics for spacer-filled membrane distillation desalination modules. Appl. Energy 2017, 185, 2045-2057. [CrossRef]

20. Chang, H.; Ho, C.D.; Hsu, J.A. Analysis of heat transfer coefficients in direct contact membrane distillation modules using CFD simulation. J. Appl. Sci. Eng. 2016, 19, 197-206.

21. Lou, Y.; Gogar, R.; Hao, P.; Lipscomb, G.; Amo, K.; Kniep, J. Simulation of net spacers in membrane modules for carbon dioxide capture. Sep. Sci. Technol. 2017, 52, 168-185. [CrossRef]

22. Fimbres-Weihs, G.A.; Wiley, D.E. Review of 3D CFD modeling of flow and mass transfer in narrow spacer-filled channels in membrane modules. Chem. Eng. Process. 2010, 49, 759-781. [CrossRef]

23. Zhou, S.J.; Li, S.; Meyer, H.; Ding, Y.; Bikson, B. Hybrid membrane/absorption process for post-combustion $\mathrm{CO}_{2}$ capture. In Proceedings of the NETL $\mathrm{CO}_{2}$ Capture Technology Meeting, Pittsburgh, PA, USA, 8-11 July 2013.

24. Fogg, P.G.T. (Ed.) Carbon Dioxide in Non-Aqueous Solvents at Pressures Less Than 200 kPA; IUPAC Solubility Data Series; Pergamon: London, UK, 1992.

25. Dindore, V.Y.; Brilman, D.W.F.; Feron, P.H.M.; Versteeg, G.F. $\mathrm{CO}_{2}$ absorption at elevated pressures using a hollow fiber membrane contactor. J. Membr. Sci. 2004, 235, 99-109. [CrossRef]

26. Koutsou, C.P.; Yiantsios, S.G.; Karabelas, A.J. A numerical and experimental study of mass transfer in spacer-filled channels Effects of spacer geometrical characteristics and Schmidt number. J. Membr. Sci. 2009, 326, 234-251. [CrossRef]

27. Da Costa, A.R.; Fane, A.G.; Wiley, D.E. Spacer characterization and pressure drop modelling in spacer-filled channels for ultrafiltration. J. Membr. Sci. 1994, 87, 79-98. [CrossRef]

28. Bird, R.B.; Stewart, W.E.; Lightfoot, E.N. Transport Phenomena, 2nd ed.; Wiley: New York, NY, USA, 2001; p. 420, ISBN 0471410772.

(C) 2017 by the authors. Licensee MDPI, Basel, Switzerland. This article is an open access article distributed under the terms and conditions of the Creative Commons Attribution (CC BY) license (http:// creativecommons.org/licenses/by/4.0/). 